\title{
New developments in the provision of family-centered care in the intensive care unit
}

\author{
RikT. Gerritsen ${ }^{1 *}$, Christiane S. Hartog ${ }^{2,3}$ and J. Randall Curtis ${ }^{4}$
}

There is increasing recognition of the important role of family members in the ICU and there are four compelling reasons that ICU clinicians should incorporate family members into the provision of critical care. First, critical illness of a loved one has enormous effects on family members of the patient with approximately one-quarter to half of family members of critically ill experiencing significant psychological symptoms, including acute stress, post-traumatic stress, generalized anxiety, and depression both during and after the critical illness of their loved one [1-3]. The combined impact on family members may result in what has been termed "post-intensive care syndrome-family" (PICS-F) [3, 4]. Importantly, clinician communication behaviors are associated with these psychological symptoms, highlighting the importance of supporting family members during critical illness [1]. Second, family members are often placed in the position of acting as surrogate decision-makers for critically ill patients and support for and effective communication with family members will facilitate high quality and ethical shared decision-making in the ICU [5]. In addition, being involved in surrogate decision-making is associated with higher levels of distress among family members and matching family preference for role in decision-making may reduce this stress $[5,6]$. Third, patients often want family members involved in decision-making about their care and most patients with chronic illness report that their family members' perspectives should take precedence over their own advance directives [7]. Finally, there is some evidence outside the ICU that supporting family members may improve patient outcomes by allowing family to be more effective caregivers $[3,8]$. For all these

\footnotetext{
*Correspondence: rtgerritsen@znb.nl

${ }^{1}$ Center of Intensive Care, Medisch Centrum Leeuwarden, Leeuwarden, The Netherlands

Full author information is available at the end of the article
}

reasons, high quality family-centered care should be considered a basic skill for ICU clinicians.

A recent clinical practice guideline about family-centered care in the ICU was produced and published the Society of Critical Care Medicine [9]. These guidelines were developed by an international multidisciplinary team of 29 members with expertise in guideline development, evidence analysis, and family-centered care. Family was defined as individuals identified by the patient to be family (not necessary following a legal or genetic definition) or, in the case of minors or those without decision-making capacity, identified by their surrogates. Furthermore, family-centered care was defined as an approach to healthcare that is respectful of and responsive to individual families' needs and values. The guideline development process was designed according to up-to-date standards for guideline development. Importantly, individuals who had been critically ill in the past and their family members were involved in reviewing the domains for the guidelines, prioritizing the outcomes to be considered, and validating the recommendations of the guidelines committee. The group performed a systematic review of the literature using the methodology of Grading of Recommendations, Assessment, Development and Evaluations (GRADE), which yielded 236 studies that were used to make 23 recommendations. All 23 of the recommendations, however, were graded as weak recommendations, reflecting the relatively low quality of evidence. Of the 23 recommendations, two were based on moderate quality evidence, 12 on low quality evidence, and nine on very low quality evidence. Table 1 shows the 14 recommendations based on moderate or low quality evidence, excluding those based on very low quality of evidence.

The five domains that were covered in these guidelines include such important areas as supporting family presence in the ICU; activities that explicitly support family

\section{Springer}


Table 1 Recommendations supported by moderate or weak quality of evidence

\begin{tabular}{|c|c|c|}
\hline Category & Recommendations & Quality of evidence ( $B=$ moderate $C=$ low) \\
\hline \multirow[t]{2}{*}{ Family presence in the ICU } & $\begin{array}{l}\text { Family members of critically ill patients be offered } \\
\text { the option of participating in interdisciplinary team } \\
\text { rounds to improve satisfaction with communica- } \\
\text { tion and increase family engagement }\end{array}$ & C \\
\hline & $\begin{array}{l}\text { Family members of critically ill patients be offered } \\
\text { the option of being present during resuscitation } \\
\text { efforts, with a staff member assigned to support } \\
\text { the family }\end{array}$ & C \\
\hline \multirow[t]{5}{*}{ Family support } & $\begin{array}{l}\text { Family members of critically ill neonates be offered } \\
\text { the option to be taught how to assist with the care } \\
\text { of their critically ill neonate to improve parental } \\
\text { confidence and competence in their caregiving } \\
\text { role and improve parental psychological health } \\
\text { during and after the ICU stay }\end{array}$ & B \\
\hline & $\begin{array}{l}\text { Family education programs be included as part of } \\
\text { clinical care as these programs have demonstrated } \\
\text { beneficial effects for family members in the ICU by } \\
\text { reducing anxiety, depression, post-traumatic stress, } \\
\text { and generalized stress while improving family } \\
\text { satisfaction with care }\end{array}$ & C \\
\hline & $\begin{array}{l}\text { ICUs provide family with leaflets that give informa- } \\
\text { tion about the ICU setting to reduce family mem- } \\
\text { ber anxiety and stress }\end{array}$ & B \\
\hline & $\begin{array}{l}\text { ICU diaries be implemented in ICUs to reduce family } \\
\text { member anxiety, depression, and post-traumatic } \\
\text { stress }\end{array}$ & C \\
\hline & $\begin{array}{l}\text { Among surrogates of ICU patients who are deemed } \\
\text { by a clinician to have a poor prognosis, clini- } \\
\text { cians use a communication approach, such as } \\
\text { the "VALUE" mnemonic (Value family statements, } \\
\text { Acknowledge emotions, Listen, Understand the } \\
\text { patient as a person, Elicit questions), during family } \\
\text { conferences to facilitate clinician-family com- } \\
\text { munication }\end{array}$ & C \\
\hline \multirow[t]{2}{*}{ Communication with family members } & $\begin{array}{l}\text { Routine interdisciplinary family conferences be used } \\
\text { in the ICU to improve family satisfaction with com- } \\
\text { munication and trust in clinicians and to reduce } \\
\text { conflict between clinicians and family members }\end{array}$ & C \\
\hline & $\begin{array}{l}\text { Healthcare clinicians in the ICU should use structured } \\
\text { approaches to communication, such as that } \\
\text { included in the "VALUE" mnemonic, when engag- } \\
\text { ing in communication with family members, } \\
\text { specifically including active listening, expressions } \\
\text { of empathy, and making supportive statements } \\
\text { around nonabandonment and decision-making. In } \\
\text { addition, we suggest that family members of criti- } \\
\text { cally ill patients who are dying be offered a written } \\
\text { bereavement brochure to reduce family anxiety, } \\
\text { depression, and post-traumatic stress and improve } \\
\text { family satisfaction with communication }\end{array}$ & C \\
\hline
\end{tabular}

\begin{tabular}{cc} 
Use of specific consultations and ICU team members & $\begin{array}{c}\text { Proactive palliative care consultation be provided to } \\
\text { decrease ICU and hospital length of stay among } \\
\text { selected critically ill patients (e.g., advanced } \\
\text { dementia, global cerebral ischemia after cardiac } \\
\text { arrest, patients with prolonged ICU stay, and } \\
\text { patients with subarachnoid hemorrhage requiring } \\
\text { mechanical ventilation) } \\
\text { Ethics consultation be provided to decrease ICU and C } \\
\text { hospital length of stay among critically ill patients } \\
\text { for whom there is a value-related conflict between } \\
\text { clinicians and family } \\
\text { Family navigators (care coordinator or communica- } \\
\text { tion facilitator) be assigned to families throughout } \\
\text { the ICU stay to improve family satisfaction with } \\
\text { physician communication, decrease psychological } \\
\text { symptoms, and reduce costs of care and length of } \\
\text { ICU and hospital stay }\end{array}$ \\
\hline
\end{tabular}


Table 1 continued

\begin{tabular}{lll}
\hline Category & Recommendations & Quality of evidence (B = moderate; $\mathbf{C}=$ low) \\
Operational and environmental issues & $\begin{array}{l}\text { Protocols be implemented to ensure adequate and } \\
\text { standardized use of sedation and analgesia during } \\
\text { withdrawal of life support }\end{array}$ \\
& $\begin{array}{l}\text { Hospitals implement policies to promote family-cen- } \\
\text { tered care in the ICU to improve family experience }\end{array}$ \\
\hline
\end{tabular}

members such as informational leaflets and ICU dairies; strategies to improve communication with family members; use of consultants or ICU team members such as ethics or palliative care consultants or family navigators, psychologists, or social workers; and operational and environmental issues such as ICU policies supporting family-centered care and standardized protocols for withdrawing life support. The guidelines committee also developed tools to enhance implementation of the research highlighted in these guidelines into clinical practice and a gap analysis tool to support translation of recommendations into practice (available at http://www. sccm.org).

There are two key take-home messages from these guidelines. First, the level of evidence supporting interventions to improve family-centered care is relatively weak. However, there are important interventions that can be recommended on the basis of the existing evidence. Second, no ICU could simultaneously implement all 14 recommendations supported by moderate or low quality evidence let alone the 23 supported by the guidelines committee. Instead, individual ICUs will need to review the recommendations and evidence, as well as their own processes of care and family-centered outcomes, to decide which interventions make the most sense given their current practice, current outcomes, the interests of the ICU team, and the resources available.

Family-centered care should be considered an important part of high quality care in every ICU. Many of the recommended strategies are based on common sense and can be implemented without significant financial investments or special equipment. However, it is important to note that some randomized trials of "common sense" interventions designed to improve family outcomessuch as a palliative care-led family conference or a condolence letter to family members of patients who died in the ICU from the ICU team-have been associated with increased psychological symptoms among family members $[10,11]$. Furthermore, some changes in clinical practice may carry the risk of increasing clinician burnout [12], as shown in an Italian pre-post study of extending family visiting hours [13]. In the future, research is needed to develop and validate more specific and responsive outcomes which can quantify benefits of improving partnerships with families and evaluate interventions designed to improve the diverse domains of familycentered care [14]. Furthermore, we need more and higher quality evidence to help identify the effective and cost-effective interventions that improve all ICU care, including family-centered care. These recent guidelines document the best available evidence to improve care for the families of critically ill patients and clearly document the need for additional research and quality improvement projects to improve this important aspect of ICU care.

\footnotetext{
Author details

${ }^{1}$ Center of Intensive Care, Medisch Centrum Leeuwarden, Leeuwarden, The Netherlands. ${ }^{2}$ Department of Anesthesiology and Intensive Care, Center for Sepsis Control and Care, Jena University Hospital, Jena, Germany. ${ }^{3}$ Patientand Family-Centered Care, Klinik Bavaria Kreischa, Kreischa, Germany. ${ }^{4}$ Cambia Palliative Care Center of Excellence, Harborview Medical Center, University of Washington, Seattle, WA, USA.
}

\section{Compliance with ethical standards}

\section{Conflicts of interest}

No authors have conflicts to report; all three are authors of the Society of Critical Care Medicine (SCCM) guideline on family-centered care (FCC).

Open Access This article is distributed under the terms of the Creative Commons Attribution-NonCommercial 4.0 International License (http:// creativecommons.org/licenses/by-nc/4.0/), which permits any noncommercial use, distribution, and reproduction in any medium, provided you give appropriate credit to the original author(s) and the source, provide a link to the Creative Commons license, and indicate if changes were made.

Received: 9 January 2017 Accepted: 10 January 2017

Published online: 25 January 2017

\section{References}

1. Lautrette A, Darmon M, Megarbane B, Jolly LM, Chevret S, Adrie C, Barnoud D, Bleichner G, Bruel C, Choukroun G, Curtis JR, Fieux F, Galliot R, Garraouste-Orgeas M, Georges H, Goldgran-Toledano D, Jourdain M, Loubert G, Reignier J, Saidi F, Souweine B, Vincent F, Barnes NK, Pochard F, Schlemmer B, Azoulay E (2007) A communication strategy and brochure for relatives of patients dying in the ICU. N Engl J Med 356:469-478

2. Davidson JE, Jones C, Bienvenu OJ (2012) Family response to critical illness: post intensive care syndrome-family. Crit Care Med 40:618-624

3. Adelman RD, Tmanova LL, Delgado D, Dion S, Lachs MS (2014) Caregiver burden: a clinical review. JAMA 311(10):1052-1060

4. Kon AA, Davidson JE, Morrison W, Danis M, White DB, American College of Critical Care Medicine, American Thoracic Society (2016) Shared decision making in ICUs: an American College of Critical Care Medicine and American Thoracic Society Policy Statement. Crit Care Med 44(1):188-201

5. Azoulay E, Pochard F, Kentish-Barnes N, Chevret S, Aboab J, Adrie C, Annane D, Bleichner G, Bollaert PE, Darmon M, Fassier T, Galliot R, 
Garrouste-Orgeas M, Goulenok C, Goldgran-Toledano D, Hayon J, Jourdain M, Kaidomar M, Laplace C, Larché J, Liotier J, Papazian L, Poisson C, Reignier J, Saidi F, Schlemmer B, FAMIREA Study Group (2005) Risk of post-traumatic stress symptoms in family members of intensive care unit patients. Am J Respir Crit Care Med 171(9):987-994

6. Gries CJ, Engelberg RA, Kross EK, Zatzick D, Nielsen EL, Downey L, Curtis JR (2010) Predictors of symptoms of posttraumatic stress and depression in family members after patient death in the ICU. Chest 137(2):280-287

7. Puchalski CM, Zhong Z, Jacobs MM, Fox E, Lynn J, Harrold J, Galanos A Phillips RS, Califf R, Teno JM (2000) Patients who want their family and physician to make resuscitation decisions for them: observations from SUPPORT and HELP. Study to understand prognoses and preferences for outcomes and risks of treatment. Hospitalized Elderly Longitudinal Project. J Am Geriatr Soc 48(5 Suppl):S84-S90

8. Lynn J (2014) Strategies to ease the burden of family caregivers. JAMA 311(10):1021-1022

9. Davidson JE, Aslakson RA, Long AC, Puntillo KA, Kross EK, Hart J, Cox CE, Wunsch H, Wickline MA, Nunnally ME, Netzer G, Kentish-Barnes N, Sprung CL, Hartog CS, Coombs M, Gerritsen RT, Hopkins RO, Franck LS, SkrobikY, Kon AA, Scruth EA, Harvey MA, Lewis-Newby M, White DB, Swoboda SM, Cooke CR, Levy MM, Azoulay E, Curtis JR (2017) Guidelines for familycentered care in the neonatal, pediatric, and adult ICU. Crit Care Med 45(1):103-128
10. Carson SS, Cox CE, Wallenstein S, Hanson LC, Danis M, Tulsky JA, Chai E, Nelson JE (2016) Effect of palliative care-led meetings for families of patients with chronic critical illness: a randomized clinical trial. JAMA 316(1):51-62

11. Kentish-Barnes N, Azoulay E (2017) Effect of a condolence letter on grief symptoms among relatives of patients who died in the ICU: a randomized clinical trial. ICME-D-16-01934 (in press)

12. Moss M, Good VS, Gozal D, Kleinpell R, Sessler CN (2016) A Critical Care Societies collaborative statement: burnout syndrome in critical care health-care professionals. A call for action. Am J Respir Crit Care Med 194:106-113

13. Giannini A, Miccinesi G, Prandi E, Buzzoni C, Borreani C, ODIN Study Group (2013) Partial liberalization of visiting policies and ICU staff: a before-and-after study. Intensive Care Med 39:2180-2187

14. Curtis JR, Downey L, Engelberg RA (2016) The importance and challenge of measuring family experience with end-of-life care in the ICU. Intensive Care Med 42(7):1179-1181 